\title{
Human Hypoxanthine-Guanine Phosphoribosyltransferase
}

\author{
DETECTION OF A MUTANT ALLELE \\ BY RESTRICTION ENDONUCLEASE ANALYSIS
}

\begin{abstract}
James M. Wilson, Philippe Frossard, Robert L. Nussbaum, C. Thomas Caskey, and William N. Kelley, Departments of Internal Medicine, Biological Chemistry, and Human Genetics, University of Michigan Medical School, Ann Arbor, Michigan 48109; Howard Hughes Medical Institute Laboratory and Departments of Medicine and Biochemistry, Baylor College of Medicine, Houston, Texas 77030
\end{abstract}

A B S TRACT We have developed a method for the direct analysis of a hypoxanthine-guanine phosphoribosyltransferase (HPRT) allele associated with a deficiency of enzyme activity and an early onset of gout. The functionally abnormal enzyme coded for by this mutant allele (HPRT Toronto $_{\text {) differs from the normal }}$ enzyme by an arginine-to-glycine substitution at position 50. A single base change in the codon for arginine 50 can explain this substitution. Direct analysis of this point mutation is based on the observation that it abolishes a Taq I recognition site in HPRT DNA. As predicted, DNA from individuals with the HPRT $_{\text {Toromto }}$ allele exhibited an abnormal restriction pattern when digested with Taq I and probed with HPRT complimentary DNA: a normal 2.0-kb fragment is replaced by a 4.0-kb fragment. The 4.0/2.0$\mathrm{kb}$ restriction fragment variation was used to detect

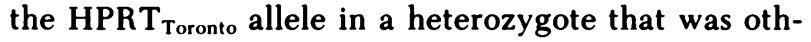
erwise normal with respect to the classical techniques used to diagnose heterozygosity in HPRT deficiency.

\section{INTRODUCTION}

Many inherited diseases are caused by defects at single genetic loci. These disorders are usually diagnosed by direct assay of the mutant gene product or by biochemical analysis of the metabolic aberrations that result from the primary defect in protein function. A more recent approach to diagnosis, which has been developed for several alleles at the $\beta$-globin locus, involves detection of the mutation of interest with spe-

Address reprint requests to Dr. William N. Kelley, Department of Internal Medicine, The University of Michigan Medical School, Ann Arbor, MI 48109.

Received for publication 24 May 1983. cific DNA probes. Prenatal diagnosis of sickle cell anemia by direct analysis of DNA in amniotic cells is the most widely celebrated example of this elegant technology. Several approaches have now been described (reviewed in reference 1). Segregation analysis of restriction fragment length polymorphisms linked to the $\beta$-globin gene has been used to identify the sickle cell allele in certain families. Restriction enzymes whose recognition sequences are altered by the sickle cell mutation can be used to directly identify the mutant gene from small quantities of DNA. More recently, Conner et al. (2) utilized synthetic oligonucleotides to specifically probe for the sickle cell mutation.

Several inborn errors of metabolism, including a deficiency of hypoxanthine-guanine phosphoribosyltransferase (HPRT), ${ }^{1}$ should also be amenable to detection at the level of genomic DNA. HPRT deficiency is an $\mathrm{X}$-linked recessive disorder that can lead to an early onset of gout (3) or, in its most severe form, the Lesch-Nyhan syndrome (4). DNA probes for the human HPRT gene are now available $(5,6)$. Nussbaum et al. (6) recently described an indirect DNA hybridization method for the detection of HPRT deficiency. Silent $\mathrm{BamHl}$ restriction fragment length polymorphisms within the HPRT structural gene were used in selected kindreds as markers for chromosomes that carry deleterious HPRT alleles. More direct gene assays can be designed for diagnosis of HPRT deficiency in those families in which the molecular basis of the disease has been defined. Mutations in the HPRT structural gene can be detected directly by selective hy-

\footnotetext{
${ }^{1}$ Abbreviations used in this paper: APRT, adenine phosphoribosyltransferase; HPRT, hypoxanthine-guanine phosphoribosyltransferase.
} 
bridization to complementary oligonucleotide probes or by restriction endonucleases whose recognition sites are altered by the mutation.

HPRT $_{\text {Toronto }}$ is a structural variant isolated from a patient with a partial deficiency of enzyme activity who presented with gout and uric acid nephrolithiasis at an early age $(7,8)$. This mutant enzyme differs from normal by an arginine-to-glycine amino acid substitution at position 50 (9). The deficiency of HPRT activity in this patient is caused by decreased levels of enzyme protein $(7,8)$ as well as increased inhibition of enzyme activity by the product guanosine monophosphate (GMP) (9). Analysis of the nucleotide sequence of HPRT complimentary (c)DNA indicated that the amino acid substitution in HPRT $\mathrm{T}_{\text {Toronto }}$ can be explained by a single base change in codon 50 . Furthermore, this point mutation abolishes a Taq I recognition site in the HPRT DNA. We describe, in this report, the use of the restriction enzyme Taq I to detect the HPRT Toronto $_{\text {mutation from genomic DNA. The }}$ utility of this approach in the detection of heterozygotes and the prenatal diagnosis of HPRT deficiency are discussed.

\section{METHODS}

Enzyme assays. Hemolysates were prepared from freshly drawn blood as described (7). Previously described radiochemical techniques were used to assay HPRT (7) and adenine phosphoribosyltransferase (APRT) (10).

Patients and DNA isolation. The clinical, genetic, and biochemical features of the $P$. family have been described (11-12). A partial pedigree of this kindred is shown in Fig. 1. DNA from a number of other individuals was screened for variation in Taq I restriction fragments. These DNA were obtained from 95 control individuals, ${ }^{2} 10$ unrelated LeschNyhan patients, and 3 previously described HPRT-deficient patients with different amino acid substitutions in the HPRT enzyme. DNA was also isolated from a cultured lymphoblast cell line derived from an individual with four $\mathrm{X}$ chromosomes (GM 1416, Human Mutant Cell Repository, Camden, NJ).

High-molecular-weight DNA was isolated from leukocytes or, when possible, cultured lymphoblasts as described (6).

cDNA probe for human HPRT. The isolation and characterization of HPRT cDNA from a human fetal liver cDNA library has been described (6). The recombinant used in this study, pHPT30, contains a 972-kb cDNA insert in the Pst I site of the plasmid vector pKT218. This HPRT cDNA contains 80 base pairs (bp) of $5^{\prime}$-noncoding sequence, the entire translated region, and $\sim 250$ bp of $3^{\prime}$-noncoding sequence. The cDNA was excised from the plasmid by digestion with Pst I and was isolated from 1\% low-melting agarose gels (Bethesda Research Laboratories, Rockville, MD) after electrophoresis. cDNA probes were labeled by nick translation under conditions recommended by the manufacturer (Bethesda Research Laboratories) with $\left.{ }^{32} \mathrm{P}\right]$ deoxycytidinetriphosphate $(3,000 \mathrm{Ci} / \mathrm{nmol}$; Amersham Corp., Arlington

\footnotetext{
${ }^{2}$ Control patients were clinically normal with respect to symptoms associated with a deficiency of HPRT.
}

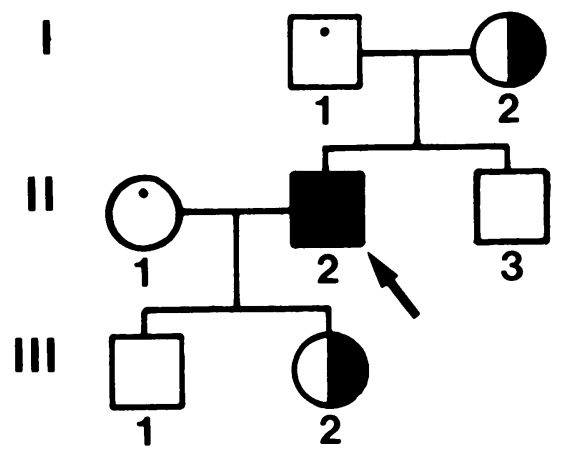

FIGURE 1 Pedigree of the P. family. Inheritance of the HPRT $_{\text {Toronto }}$ mutation is indicated: hemizygote, shaded symbol; heterozygotes, one-half of symbol shaded; normal individuals, open symbols. Patients unavailable for study are indicated by the dot in the upper portion of the symbol; the propositus is indicated by the arrow.

Heights, IL) in the presence of unlabeled deoxyadenosine triphosphate/deoxyguanosine triphosphate/deoxythymidine triphosphate to a specific activity of $1-3 \times 10^{8}$ $\mathrm{cpm} / \mu \mathrm{g}$.

Blot hybridization analysis of genomic DNA. High-molecular-weight DNA was digested to completion with Taq I under conditions recommended by the manufacturer (Bethesda Research Laboratories). Restriction digests were fractionated in $0.8 \%$ agarose gels, and DNA fragments were transferred to nitrocellulose paper by the method of Southern (13) and probed with ${ }^{32} \mathrm{P}$-labeled cDNA under the following conditions. Filters were prehybridized in $5 \times$ SSPE ( $1 \times \mathrm{SSPE}$ is $10 \mathrm{mM} \mathrm{NaH}_{2} \mathrm{PO}_{4}$, pH 7.4 plus $0.18 \mathrm{M} \mathrm{NaCl}$ and $1 \mathrm{mM}$ EDTA), containing $5 \times$ Denhardt's solution $(1 \times$ Denhardt's solution contains $1 \mathrm{mg} / \mathrm{ml}$ of Ficoll, polyvinylpyrrolidone, and bovine serum albumin), $35 \%$ (vol/vol) formamide, and sheared and denatured salmon sperm DNA (250 $\mu \mathrm{g} / \mathrm{ml}$ ), and were hybridized in $5 \times$ SSPE containing $1 \times$ Denhardt's solution, $35 \%$ (vol/vol) formamide, $10 \%$ dextran sulfate, and sheared and denatured salmon sperm DNA (100 $\mu \mathrm{g} / \mathrm{ml}$ ) mixed with the ${ }^{32} \mathrm{P}$-labeled probe. Prehybridization and hybridization were performed at $42^{\circ} \mathrm{C}$. Washes were performed twice at room temperature in $2 \times$ standard saline citrate ( $1 \times$ standard saline citrate is $0.15 \mathrm{M} \mathrm{NaCl} / 0.015 \mathrm{M}$ sodium citrate, $\mathrm{pH} 7.4)$ and twice at $65^{\circ} \mathrm{C}$ in $2 \times$ standard saline citrate containing $1 \times$ Denhardt's solution.

\section{RESULTS}

Activity of HPRT and APRT in erythrocytes from the P. family. Table I summarizes the activity of HPRT and APRT in hemolysates obtained from the $P$. family. The propositus exhibited a decreased activity of HPRT and an increased activity of APRT; his unaffected brother had normal levels of both enzymes. His mother, a known heterozygote, exhibited an intermediate deficiency of HPRT and an elevated activity of APRT, while his daughter, an obligate heterozygote, was normal with respect to both HPRT and APRT. 
TABLE I

Activity of HPRT and APRT in the P. Family

\begin{tabular}{lcccc}
\hline \multicolumn{1}{c}{ Subjects } & \multicolumn{2}{c}{ HPRT activity } & \multicolumn{2}{c}{ APRT activity } \\
\hline & $m U / m g$ & $\%$ control & $m U / m g$ & $\%$ control \\
& & & & \\
Control & $1.75 \pm 0.25(15)^{\bullet}$ & 100 & $0.46 \pm 0.07(12) \downarrow$ & 100 \\
Propositus (II-2) & 0.44 & 25 & 0.70 & 152 \\
Mother (I-2) & 1.52 & 87 & 0.67 & 146 \\
Brother (II-3) & 1.82 & 104 & 0.35 & 76 \\
Daughter (III-2) & 1.80 & 103 & 0.40 & 87 \\
\hline
\end{tabular}

- Mean \pm 1 SD for 15 determinations of four control subjects.

† Mean \pm 1 SD for 12 control subjects. Taken from reference 10 .

Detection of the HPRT Toronto mutation with the restriction enzyme Taq I. Deficiency of HPRT activity in the P. family is caused by a single amino acid substitution, arginine to glycine, at position 50 of the enzyme (9). An analysis of the nucleotide sequence of HPRT cDNA (5) indicated that the proposed substitution can be explained by a single nucleotide change in the codon for arginine-50. Furthermore, we predict that this point mutation would obliterate a recognition site for the endonuclease Taq I (Fig. 2).

Taq I digests of DNA isolated from several normal male subjects were analyzed by the method of Southern and were probed with near full-length HPRT cDNA (Fig. 3, lanes $B$ and $C$ ). This cDNA probe clearly hybridized to restriction fragments of $4.6,3.7,2.0,1.5$, 1.1 , and $0.7 \mathrm{~kb}$ in length. Fainter bands were also consistently detected at 16.0 and $0.5 \mathrm{~kb}$. Previous studies have identified autosomal sequences that are recognized by the HPRT cDNA (6). DNA from an individual with four $\mathrm{X}$ chromosomes was analyzed in parallel with the XY controls to help define Taq I restriction fragments that are $\mathrm{X}$-linked and therefore derived from the HPRT gene (lane $A$ ). Relative band intensities were quantitated by scanning densitometry (data

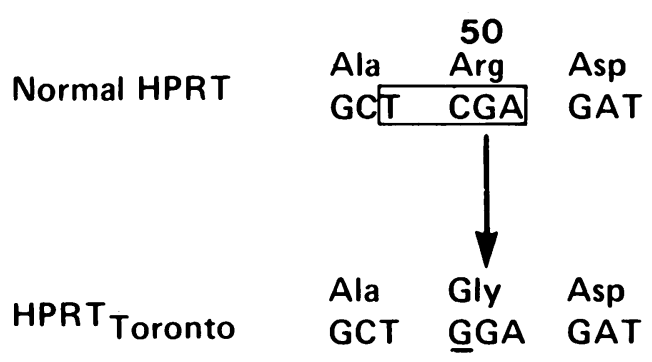

Figure 2 Predicted alteration in Taq I recognition site from HPRT $_{\text {Toronto DNA. Nucleotide sequence of normal HPRT }}$ cDNA was taken from reference (6). The Taq I recognition site in normal HPRT DNA is indicated by the rectangle. A, adenine; $\mathrm{C}$, cytosine; $\mathrm{G}$, guanine; $\mathrm{T}$, thymine.

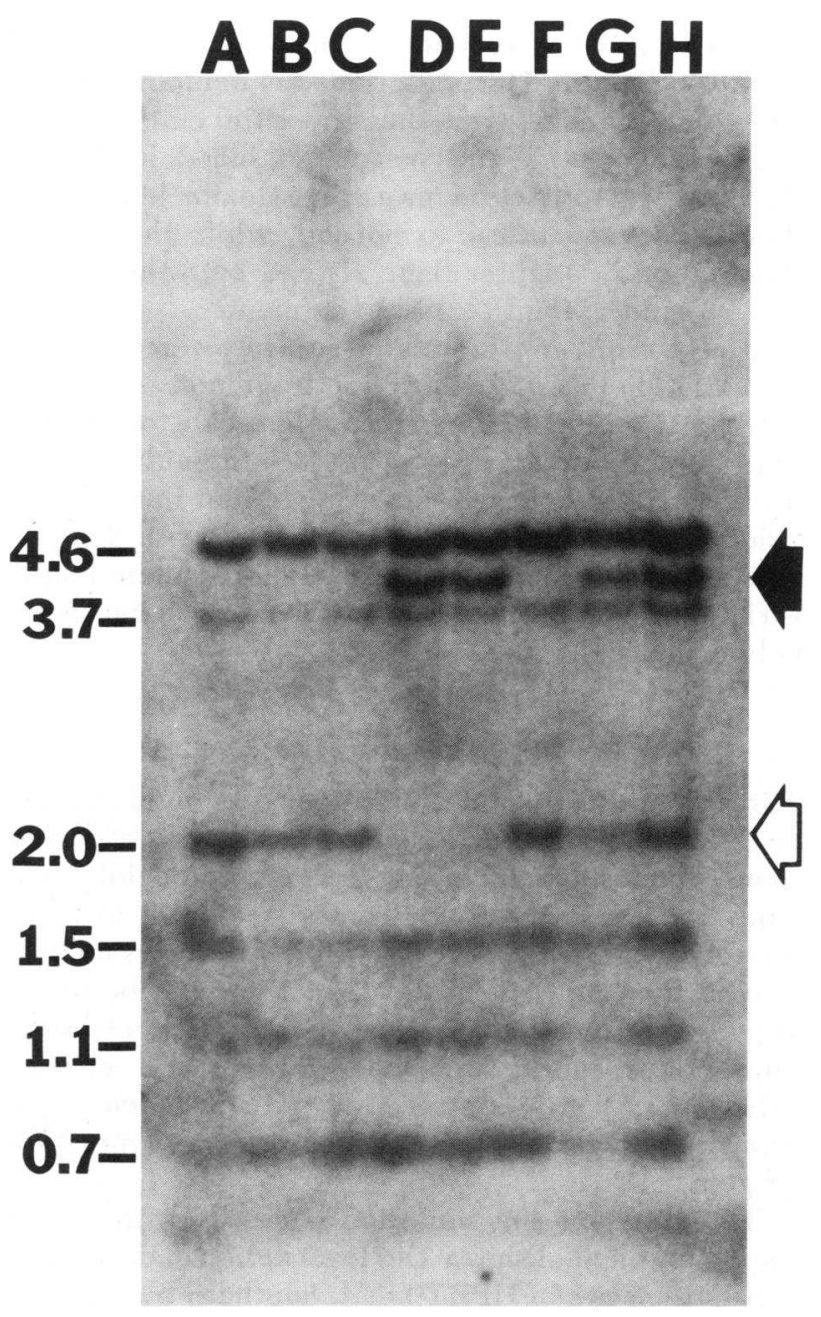

Figure 3 Autoradiogram of Taq I digested normal and mutant DNA. DNA was digested with Taq I and analyzed for restriction fragments that hybridized to HPRT cDNA as described in Methods. Electrophoresis was performed in an $8 \times 16-\mathrm{cm}$ agarose gel; $\sim 5 \mathrm{~g}$ of DNA was loaded into each well. Lane $A-$ cultured lymphoblasts (GM 1416) of a patient with four $\mathrm{X}$ chromosomes; lanes $B$ and $C$ cultured lymphoblasts of two control patients; lane $D$-cultured lymphoblasts from the propositus; lane $E$-leukocytes from the propositus; lane $F$-leukocytes from the unaffected brother; lane $G-$ leukocytes from the mother; and lane $\mathrm{H}$-leukocytes from the daughter. Restriction fragments that demonstrate variation are indicated by an open $(2.0 \mathrm{~kb})$ and closed $(4.0 \mathrm{~kb})$ arrow, respectively. Restriction fragment lengths, which are indicated along the left border, were determined by comparison with DNA fragments of known size.

not shown). Restriction fragments of 2.0 and $1.5 \mathrm{~kb}$ in length clearly exhibited an increased signal, consistent with the dosage of $\mathrm{X}$ chromosomes.

Restriction maps of DNA isolated from the propositus differed from normal by the absence of the $2.0-\mathrm{kb}$ 
fragment and the appearance of a new fragment of $4.0 \mathrm{~kb}$ in length. This variation was demonstrated in two different tissues from the propositus: cultured lymphoblasts (lane $D$ ) and peripheral blood leukocytes (lane $E$ ). The restriction map of the unaffected brother (lane $F$ ) was identical to normal, while the mother (lane $G$ ) and daughter (lane $H$ ) had both the normal $(2.0-\mathrm{kb})$ and variant $(4.0-\mathrm{kb})$ fragments.

A large number of unrelated subjects were screened for variation in Taq I restriction fragments. These experiments were performed on a microscale to conserve time and resources. A total of 108 individuals have been tested without detectable variation in Taq I restriction fragment lengths (data not shown). This indicates that the 4.0/2.0-kb restriction fragment length variation detected in the $\mathrm{P}$. family is probably not a polymorphism.

\section{DISCUSSION}

Direct identification of mutant genes by hybridization to DNA probes has been used in the diagnosis of several genetic disorders including certain hemoglobinopathies and thalassemia syndromes (reviewed in reference 1) and more recently a form of diabetes mellitus caused by a mutant insulin (14). We describe in this report a sensitive assay for a mutant allele of HPRT that codes for a functionally abnormal enzyme

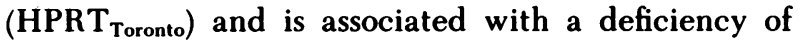
enzyme activity and an early onset of a severe form of gout.

The assay for this mutation is based on the observation that it abolishes a Taq I restriction endonuclease recognition site in HPRT DNA. Southern blot analysis of DNA digested with Taq I and probed with HPRT cDNA provided a direct and sensitive method for detecting the HPRT Toronto $_{\text {allele. Several important fea- }}$ tures of the Taq I assay are worth mentioning. The successful demonstration of Taq I restriction fragment length variation in this patient provided independent confirmation of the arginine-to-glycine substitution at position 50 , previously identified by protein sequencing (9). In addition, due to the ease and sensitivity of this assay, it will now be possible to screen rapidly a large population of gouty individuals for the same mutation. Finally, as described below, the Taq I assay provided a direct approach for detection of subjects heterozygous for this allele.

Previously described methods for detecting heterozygotes for a deficiency of HPRT are indirect and fraught with difficulties. Random inactivation of the $\mathrm{X}$ chromosome in HPRT-deficient heterozygotes produces cells with either normal or diminished HPRT activity. One approach to heterozygote detection is based on the demonstration of this mixed population of cells in possible carriers. Mosaicism with respect to HPRT activity can be demonstrated in cultured fibroblasts by measuring the incorporation of radiolabeled hypoxanthine into nucleic acids (15) or the relative cellular sensitivity to toxic purine analogues (16). Mosaicism can also be demonstrated by analysis of hair roots (17). Although these techniques have been successful in detecting heterozygotes for the Lesch-Nyhan syndrome, they lack the sensitivity necessary to differentiate normal cells from cells with a partial deficiency of HPRT, and therefore have proven to be inadequate in the diagnosis of some patients that are hemizygous or heterozygous for the partial enzyme defect. Another indirect approach to heterozygote detection, which also has had limited application, is the assay of HPRT in peripheral blood (erythrocytes and leukocytes). It appears that hemopoietic precursor cells with a marked deficiency of HPRT are unable to proliferate in the presence of cells with HPRT activity (18). As a result, HPRT activity is normal in peripheral blood of Lesch-Nyhan heterozygotes (19). Several investigators have measured intermediate levels of HPRT activity in hemolysates from subjects heterozygous for the partial enzyme defect, indicating that selection against HPRT-deficient cells in bone marrow is not always complete (reviewed in reference 20). Hemolysate HPRT and APRT activity measurements may therefore help in diagnosing the heterozygous state in certain individuals. ${ }^{3}$ Normal enzyme activity, however, does not exclude heterozygosity since there exists tremendous inter- and intrafamily variation (21).

Previous attempts at identifying heterozygotes for the HPRT Toronto $_{\text {allele illustrate the limitations of the }}$ current technology. Fox et al. (11) demonstrated that cultured fibroblasts derived from the propositus are indistinguishable from normal fibroblasts with respect to incorporation of $\left[{ }^{3} \mathrm{H}\right]$ hypoxanthine into nucleic acids and relative sensitivity to azaguanine. Detection of heterozygotes by conventional analysis of fibroblasts was therefore impossible. Indirect evidence that the mother of the propositus is heterozygous for the HPRT $_{\text {Toronto }}$ allele was first provided by electrophoretic analysis of her hemolysate, which demonstrated the existence of the mutant enzyme (12). Enzyme activity measurements are consistent with this observation; hemolysate from the mother exhibited an intermediate decrease in HPRT activity and an associated elevation in APRT. However, the daughter of the propositus, an obligate heterozygote, had normal levels of HPRT and APRT activity in hemolysate. Several investigators

\footnotetext{
${ }^{3}$ We and others have shown that a deficiency of HPRT activity in erythrocytes is always associated with an elevation in the activity and concentration of APRT (reviewed in reference 20 ).
} 
have noted similar intrafamily variation in HPRT and APRT activity of obligate HPRT-deficient heterozygotes (32). Direct analysis of the HPRT structural genes in these family members by the Taq I assay provided direct and unequivocal evidence for the genotype of the propositus, the heterozygotes (mother and daughter), and the unaffected brother.

Detection of mutant HPRT alleles by DNA hybridization provides an alternative approach for prenatal diagnosis of the more severe form of HPRT deficiency, the Lesch-Nyhan syndrome. Nussbaum et al. (6) recently described the use of silent restriction fragment length polymorphisms as markers for the indirect identification of deleterious HPRT alleles. We have illustrated in this report a direct approach for identifying mutations that affect restriction endonuclease recognition sites. A powerful technique, which may have application in the detection of other defined mutations at the HPRT locus, is the differential hybridization of complementary oligonucleotide probes. An important feature of direct gene analysis, as it relates to prenatal diagnosis, is the sensitivity of the technique. In contrast to the conventional methods of prenatal diagnosis of HPRT deficiency, which require propagation of amniotic cells in vitro for several weeks, analysis of mutant alleles by DNA hybridization can be performed directly on cells obtained from 5-10 ml of amniotic fluid. Taq I analysis of DNA isolated from amniotic fluid of two normal fetuses has in fact been done. ${ }^{4}$

In conclusion, we have developed a DNA hybridization assay for detecting the HPRT Toronto $_{\text {mutation }}$ from small quantities of genomic DNA. This provided independent confirmation of the mutation in this variant allele, previously defined by protein sequence analysis. Finally, we used this assay to detect a heterozygote that was otherwise normal with respect to the classical techniques used to diagnose heterozygosity in HPRT deficiency.

\section{ACKNOWLEDGMENTS}

We would like to thank the members of T. Caskey's research group for their guidance and suggestions.

This work was supported by grant RO 1-AM 1905 from the National Institutes of Health and by the Howard Hughes Foundation. Dr. Wilson was supported by the Medical Scientist Training Program at the University of Michigan.

\section{REFERENCES}

1. Kronenberg, H. M. 1983. Looking at genes. N. Engl. J. Med. 307:50-52.

2. Conner, B. J., A. A. Reyes, C. Morin, K. Itakura, R. L.

${ }^{4}$ Wilson, J. M. Unpublished observations.
Teplitz, and R. B. Wallace. 1983. Detection of sickle cell

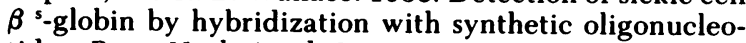
tides. Proc. Natl. Acad. Sci. USA. 80:278-282.

3. Kelley, W. N., F. M. Rosenbloom, J. F. Henderson, and J. E. Seegmiller. 1967. A specific enzyme defect in gout associated with overproduction of uric acid. Proc. Natl. Acad. Sci. USA. 57:1735-1739.

4. Seegmiller, J. E., F. M. Rosenbloom, and W. N. Kelley. 1967. Enzyme defect associated with a sex-linked human neurological disorder and excessive purine synthesis. Science (Wash. DC). 155:1682-1684.

5. Jolly, D. J., H. Okayama, P. Berg, A. C. Esty, D. Filpula, P. Bohlen, G. G. Johnson, J. E. Shively, T. Hunkapiller, and $T$. Friedmann. 1982. Isolation and characterization of a full-length expressible cDNA for human hypoxanthine-guanine phosphoribosyltransferase. Proc. Natl. Acad. Sci. USA. 80:477-481.

6. Nussbaum, R. L., W. E. Crowder, W. L. Nyhan, and C. T. Caskey. 1983. A three-allele restriction fragment length polymorphism at the hypoxanthine phosphoribosyl locus in man. Proc. Natl. Acad. Sci. USA. 80:40354039.

7. Wilson, J. M., B. W. Baugher, L. Landa, and W. N. Kelley. 1981. Human hypoxanthine-guanine phosphoribosyltransferase: purification and characterization of mutant forms of the enzyme. J. Biol. Chem. 256:1030610312 .

8. Wilson, J. M., B. W. Baugher, P. M. Mattes, P. E. Daddona, and W. N. Kelley. 1982. Human hypoxanthineguanine phosphoribosyltransferase: demonstration of structural variants in lymphoblastoid cells derived from patients with a deficiency of the enzyme. J. Clin. Invest. 69:706-715.

9. Wilson, J. M., R. Kobayashi, I. H. Fox, and W. N. Kelley. 1983. Human hypoxanthine-guanine phosphoribosyltransferase: molecular abnormality in a mutant form of

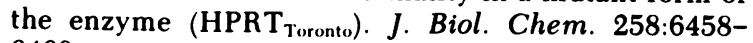
6460.

10. Wilson, J. M., P. E. Daddona, H. A. Simmonds, K. J. VanAcker, and W. N. Kelley. 1982. Human adenine phosphoribosyltransferase: immunochemical quantitation and protein blot analysis of mutant forms of the enzyme. J. Biol. Chem. 257:1508-1515.

11. Fox, I. H., I. L. Dwosh, P. J. Marchant, S. Lacroix, M. R. Moore, S. Omura, and V. Wyhofsky. 1975. Hypoxanthine-guanine phosphoribosyltransferase. Characterization of a mutant in a patient with gout. J. Clin. Invest. 56:1239-1249.

12. Fox, I. H., P. J. Marchant, and S. Lacroix. 1976. Hypoxanthine-guanine phosphoribosyltransferase: mosaicism in the peripheral erythrocytes of a heterozygote for a normal and a mutant enzyme. Biochem. Genet. 14:587-593.

13. Southern, E. M. 1975. Detection of specific sequences among DNA fragments separated by gel electrophoresis. J. Mol. Biol. 98:503-517.

14. Shoelson, S., M. Haneda, P. Blinx, A. Nanjo, T. Sanke, K. Inouye, D. Steiner, A. Rubenstein, and $H$. Tager 1983. Three mutant insulins in man. Nature (Lond.). 302:540-543.

15. Rosenbloom, F. M., W. N. Kelley, J. F. Henderson, and J. E. Seegmiller. 1967. Lyon hypothesis and X-linked disease. Lancet. II:305-306.

16. Migeon, B. R. 1970. X-linked hypoxanthine-guanine phosphoribosyltransferase deficiency: detection of heterozgotes by selective medium. Biochem. Genet. 4:377383. 
17. Gartler, S. M., R. C. Scott, J. L. Goldstein, and B. Campbell. 1971. Lesch-Nyhan syndrome: rapid detection of heterozygotes by use of hair follicles. Science (Wash. DC). 172:572-574.

18. Nyhan, W. L., B. Bakay, J. D. Conner, J. F. Marks, and D. K. Keele. 1970. Hemizygous expression of glucose-6phosphate dehydrogenase in erythrocytes of heterozygotes for the Lesch-Nyhan syndrome. Proc. Natl. Acad. Sci. USA. 65:214-218.

19. Kelley, W. N. 1968. Hypoxanthine-guanine phosphoribosyltransferase deficiency in the Lesch-Nyhan syndrome and gout. Fed. Proc. 27:1047-1052.
20. Kelley, W. N., and J. B. Wyngaarden. 1983. Clinical syndromes associated with a deficiency of hypoxanthineguanine phosphoribosyltransferase. In The Metabolic Basis of Inherited Disease. J. B. Stanbury, J. B. Wyngaarden, J. B. Fredrickson, J. L. Goldstein, and D. S. Brown, editors. McGraw-Hill Book Co., New York. Fifth ed. 1115-1143.

21. Emmerson, B. T., C. J. Thompson, and D. C. Wallace. 1972. Partial deficiency of hypoxanthine-guanine phosphoribosyltransferase: intermediate enzyme deficiency in heterozygote red cells. Ann. Intern. Med. 76:285287. 